\title{
Association between TNIP1, MPHOSPH6 and ZNF208 genetic polymorphisms and the coronary artery disease risk in Chinese Han population
}

\author{
Yanbin Song ${ }^{1,2,3}$, Mengdan Yan ${ }^{1,2}$, Jing Li ${ }^{1,2}$, Jingjie $\mathrm{Li}^{1,2}$, Tianbo Jin ${ }^{1,2}$ and Chao Chen ${ }^{1,2}$ \\ ${ }^{1}$ Key Laboratory of Resource Biology and Biotechnology in Western China (Northwest University), Ministry of Education, \\ Xi'an, Shaanxi 710069, China \\ ${ }^{2}$ School of Life Sciences, Northwest University, Xi'an, Shaanxi 710069, China \\ ${ }^{3}$ Department of Cardiovascular, Yanan University Affiliated Hospital, Yanan, Shaanxi 716000, China \\ Correspondence to: Tianbo Jin, email: tianbojin1973@163.com \\ Chao Chen, email: chaochenxd@gmail.com \\ Keywords: coronary artery disease (CAD), polymorphisms, ZNF208, TNIP1, MPHOSPH6 \\ $\begin{array}{lll}\text { Received: May 18, } 2017 \quad \text { Accepted: June 24, } 2017 & \text { Published: August 24, } 2017\end{array}$ \\ Copyright: Song et al. This is an open-access article distributed under the terms of the Creative Commons Attribution License 3.0 \\ (CC BY 3.0), which permits unrestricted use, distribution, and reproduction in any medium, provided the original author and source \\ are credited.
}

\section{ABSTRACT}

Introduction: Coronary artery disease (CAD) is a common disease and among the leading cause of death in the general population. Inherited factors are involved in the pathogenesis of CAD.

Aims: Our study examined whether SNPs in TNIP1, MPHOSPH6, ZNF208 to be associated with CAD risk in a Chinese Han population. We recruited 596 CAD patients, 603 controls and genotyping fifteen SNPs using Sequenom MassARRAY. For association analysis between TNIP1, MPHOSPH6 and ZNF208 and CAD was determined by Odds ratios (ORs) with $95 \%$ confidence intervals (CIs) using Logistic Regression.

Results: The results indicated in allel model, the rs960709 in TNIP1 was associated with CAD risk $(\mathrm{OR}=0.78,95 \% \mathrm{CI}=0.65-0.94, \mathrm{P}=0.010)$. The genetic model results showed that the rs960709 (A/G) polymorphism was associated with the risk of developing CAD in codominant, Dominant and Log-additive. The rs1056654 $A / A$ allele and CAD patients compared to the healthy controls in recessive model (OR $=0.55,95 \% \mathrm{CI}=0.34-0.90 ; \mathrm{P}=0.018)$. We also found that three SNPS in ZNF208 associated with CAD, respectively, rs2188971, rs8103163 and rs7248488.

Linkage disequilibrium (LD) and haplotype analyses of the SNPs found that the CTA haplotype (rs1056675, rs1056654, rs11859599) and rs2188972A/rs2188971T/ rs8103163A/rs7248488A (ATAA) were associated with CAD.

Conclusion: In conclusion, the present study provided evidence that SNPs in the TNIP1, ZNF208 and MPHOSPH6 were associated with CAD in Chinese Han population. It is possible that these SNPs are CAD risk factors and these data can provide.

\section{INTRODUCTION}

Coronary artery disease (CAD) is a common disease, and among the leading cause of death in the general population [1]. It is the most common form of heart disease known that as a complex disease. There are many risk factors for coronary heart disease, including alcoholism, family history, hypertension, diabetes mellitus and hyperlipidemia [2]. It is generally believed that CAD and its related risk factors are largely genetic controlled [3]. Whereas only few of individuals with the risk factors of CAD eventually develop this disease. Therefore, inherited factors participate in the pathogenesis of CAD [4]. Telomeric DNA is located at the end of chromosomes, consists of TTAGGG tandem repeats, although the full extent of their functions is not fully understood and is important for maintaining genomic stability.

$\mathrm{CAD}$ is an age related disease. In humans, telomere shortening is regarded as a predictor of aging and aging- 
Table 1: Characteristics of cases and controls in this study

\begin{tabular}{lccc}
\hline Variables & Cases $(\mathbf{N})$ & Controls $(\mathbf{N})$ & $\boldsymbol{p}$ \\
\hline Subjects & 596 & 603 & $<0.001$ \\
Gender & & & 134 \\
$\quad$ Female & 220 & 469 & $<0.001$ \\
Male & 376 & $48.24 \pm 13.05$ & \\
Age \pm SD & $61.44 \pm 11.16$ & & \\
\hline
\end{tabular}

$p$ value $\leq 0.05$ indicates statistical significance.

Table 2: PCR primers

\begin{tabular}{|c|c|c|c|}
\hline SNP & 1st-PCR primer sequences & 2st-PCR primer sequences & UEP sequences \\
\hline rs3792792 & ACGTTGGATGCTCAGATCAGTTCACTCCTC & ACGTTGGATGATGGCAGCTGTTACGGCCAC & ccctTTACGGCCACCACCAAGCATG \\
\hline rs4958881 & ACGTTGGATGCACAAATATGTGGACAGTTT & ACGTTGGATGTGCAATTCCACCCAAGGATG & GGATGAAAGGAAGTGAGA \\
\hline rs7708392 & ACGTTGGATGAGGCCAACTGGTCAATTCTC & ACGTTGGATGGGGTCTCTTCTGGAACTTAG & ggggaTGGAACTTAGTAGACTAGTCA \\
\hline rs10036748 & ACGTTGGATGGCAAAGCAGCCCCTTTTTTC & ACGTTGGATGCTTTCATAGCATGATACACG & ACGTATGAGAAAAATAAAATAGTAA \\
\hline rs960709 & ACGTTGGATGTATGGGTCTTTTCAGCTCGG & ACGTTGGATGTAAGCCAGAGCTGGAGCTCA & atAGTTCCGTCCAGGGC \\
\hline rs 1056675 & ACGTTGGATGAATACTTAAGGCTGGAGAGG & ACGTTGGATGGTCAAGCCAATTCGTACATAC & ggtgCGTACATACAATTTGGAATCAA \\
\hline rs 1056654 & ACGTTGGATGGTATGTACGAATTGGCTTGAC & ACGTTGGATGCAGTCACTGACCTTGAATTG & ACCTTGAATTGACTTACATAAA \\
\hline rs 1056629 & ACGTTGGATGTTTTTAGCCCCTGATCTAC & ACGTTGGATGGGTCAGTGACTGGAGAACTA & cGGAAGCAGCCCTGTAACAA \\
\hline rs 3751862 & ACGTTGGATGTGGTGTCTCTATAGTTATT & ACGTTGGATGCATCTGTTTCAAAAACAGC & TGTTTCTAAAATGATAATCTCTTTACA \\
\hline rs11859599 & ACGTTGGATGTAAGAGAAGGCCGATCACAG & ACGTTGGATGCCCAGGAATGCTCCTCTTAC & ССТСТTACСCCACAGT \\
\hline rs2967361 & ACGTTGGATGTTACTGGGAACCAGCTTACG & ACGTTGGATGAGCTGTACCCTGACTGCTTC & tCCTGACTGCTTCTGTGTAC \\
\hline rs2188972 & ACGTTGGATGGGCTTGATTGGTCAAATGGC & ACGTTGGATGATTCAGAACCTGTGCAAAGC & GACTTCTCAAAGAACTAGAAA \\
\hline rs2188971 & ACGTTGGATGCTCTTCAAAGATCTACTTC & ACGTTGGATGCACTAAATCAGACTGCTGAG & TCCAAAACTAAAGTTGGCAAAA \\
\hline rs8103163 & ACGTTGGATGCCAGAAGATCTGAGATAAAG & ACGTTGGATGTTTTGGGCCAAAAACTTTG & cctGCCAAAAACTTTGGCATACT \\
\hline rs 7248488 & ACGTTGGATGGTTCTCCAGGAACACTTATG & ACGTTGGATGGCAGAGTGTTTTCCTGGTTG & GTCATGATGAGAAGGGT \\
\hline
\end{tabular}

related diseases [5]. Many previous studies have suggested that a relatively short telomere length (TL) is associated with a higher risk of developing aging-related chronic diseases, particularly cardiovascular dysfunctions [6-9]. Observationally, short telomeres are associated with an increased risk of ischemic heart disease [8, 10, 11]. Genetic variants implicated in TL have been reported to be associated with the incidence of aging-related chronic diseases [12]. For example, the study found rs $10786775 \mathrm{C}$ $>\mathrm{G}$, rs11591710 A > C single nucleotide polymorphisms (SNPs) in OBFC1 were associated with a higher risk of developing coronary heart CAD, and rs12696304 C > $\mathrm{G}, \mathrm{rs} 10936601 \mathrm{G}>\mathrm{T}$, rs16847897 G > C SNPs in TERC were correlated with a higher risk of CAD and the type II diabetes mellitus (T2DM) [13]. It was also reported that genetic variations in TERT were significantly correlated with CAD in a Japanese case study [14]. Individual differences in telomere length in rodents $[15,16]$ and humans [17-20] suggest that this parameter is genetically determined. While evidence for the causal role of TL variation in some chronic diseases has accumulated [21], the link between TNIP1, MPHOSPH6, ZNF208 SNPs and CAD risk, has not been extensively studied in Chinese populations. In the study, we examined whether SNPs in TNIP1, MPHOSPH6, ZNF208 to be associated with CAD risk in a Chinese Han population.

\section{RESULTS}

The comparison of basic characteristics data of the controls and CAD groups is given in Table 1. Age and sex difference were statistically significant. Table 3 summarizes the distributions of SNPs genotypes, allele frequencies and the basic information for two groups. The distribution of rs4958881 (TNIP1), rs1056629 (MPHOSPH6) in control subjects was not in the HardyWeinberg equilibrium and the rest of the SNP distribution complied with the Hardy-Weinberg equilibrium. In allel model, we found the rs960709 in TNIP1 was associated with $\mathrm{CAD}$ risk, and had a 0.78 fold risk of CAD $(\mathrm{OR}=$ $0.78,95 \% \mathrm{CI}=0.65-0.94, \mathrm{P}=0.010)$. 
Table 3: Basic information of candidate SNPs in this study

\begin{tabular}{|c|c|c|c|c|c|c|c|c|c|}
\hline SNP & Chr & $\operatorname{Allel}\left(\mathbf{A}^{\mathrm{a}} / \mathbf{B}\right)$ & Gene & MAF(Case) & MAF(Control) & HWE(P) & OR & $95 \% \mathrm{CI}$ & $\mathbf{P}$ \\
\hline rs3792792 & $5 \mathrm{q} 33.1$ & $\mathrm{C} / \mathrm{T}$ & TNIP1 & 0.0595638 & 0.064676617 & 0.302 & 0.92 & $0.66-1.28$ & 0.604 \\
\hline rs4958881 & $5 \mathrm{q} 33.1$ & $\mathrm{C} / \mathrm{T}$ & TNIP1 & 0.0713087 & 0.105982906 & $5.33 \mathrm{E}-74$ & 0.65 & $0.49-0.86$ & 0.003 \\
\hline rs7708392 & $5 \mathrm{q} 33.1$ & $\mathrm{G} / \mathrm{C}$ & TNIP1 & 0.2508389 & 0.233001658 & 0.820 & 1.10 & $0.91-1.33$ & 0.308 \\
\hline rs 10036748 & $5 \mathrm{q} 33.1$ & $\mathrm{C} / \mathrm{T}$ & TNIP1 & 0.2516779 & 0.233001658 & 0.820 & 1.11 & $0.92-1.33$ & 0.286 \\
\hline rs960709 & $5 \mathrm{q} 33.1$ & $\mathrm{~A} / \mathrm{G}$ & TNIP1 & 0.2533898 & 0.301886792 & 0.304 & 0.78 & $0.65-0.94$ & 0.010 \\
\hline rs1056675 & $16 \mathrm{q} 23.3$ & $\mathrm{C} / \mathrm{T}$ & MPHOSPH6 & 0.4253356 & 0.430116473 & 1.000 & 0.98 & $0.83-1.15$ & 0.813 \\
\hline rs1056654 & $16 \mathrm{q} 23.3$ & $\mathrm{~A} / \mathrm{G}$ & MPHOSPH6 & 0.272651 & 0.290697674 & 0.323 & 0.91 & $0.77-1.09$ & 0.326 \\
\hline rs1056629 & $16 \mathrm{q} 23.3$ & $\mathrm{C} / \mathrm{T}$ & MPHOSPH6 & 0.272651 & 0.266221374 & 2.39E-08 & 1.03 & $0.86-1.25$ & 0.732 \\
\hline rs 3751862 & $16 \mathrm{q} 23.3$ & $\mathrm{C} / \mathrm{A}$ & MPHOSPH6 & 0.0564924 & 0.042358804 & 0.287 & 1.35 & $0.93-1.97$ & 0.111 \\
\hline rs11859599 & $16 \mathrm{q} 23.3$ & $\mathrm{C} / \mathrm{G}$ & MPHOSPH6 & 0.2432886 & 0.23880597 & 0.093 & 1.02 & $0.85-1.24$ & 0.797 \\
\hline rs2967361 & $16 \mathrm{q} 23.3$ & $\mathrm{~T} / \mathrm{G}$ & MPHOSPH6 & 0.2567114 & 0.23255814 & 0.425 & 1.14 & $0.95-1.37$ & 0.169 \\
\hline rs2188972 & $19 \mathrm{p} 12$ & $\mathrm{G} / \mathrm{A}$ & ZNF208 & 0.5184564 & 0.487562189 & 0.415 & 1.13 & $0.96-1.33$ & 0.130 \\
\hline rs2188971 & $19 \mathrm{p} 12$ & $\mathrm{~T} / \mathrm{C}$ & ZNF208 & 0.329698 & 0.302325581 & 0.700 & 1.14 & $0.96-1.35$ & 0.150 \\
\hline rs8103163 & $19 \mathrm{p} 12$ & $\mathrm{~A} / \mathrm{C}$ & ZNF208 & 0.3288591 & 0.3026534 & 0.772 & 1.13 & $0.95-1.34$ & 0.167 \\
\hline rs7248488 & $19 \mathrm{p} 12$ & $\mathrm{~A} / \mathrm{C}$ & ZNF208 & 0.329698 & 0.303482587 & 0.631 & 1.13 & $0.95-1.34$ & 0.168 \\
\hline
\end{tabular}

a Minor allele; MAF, minor allelic frequency; HWE, Hardy-Weinberg equilibrium; ORs, odds ratios; CI: confidence interval.

HWE $p$-value $\leq 0.05$ was excluded; $p$ value $\leq 0.05$ indicates statistical significance.

Table 4: Association between significant SNPs and risk of CAD in genetics models

\begin{tabular}{|c|c|c|c|c|c|c|}
\hline SNP & Model & Genotype & control & case & OR $(95 \%$ CI $)$ & P-value \\
\hline \multirow[t]{8}{*}{ rs960709 } & Codominant & $\mathrm{G} / \mathrm{G}$ & $253(47.7 \%)$ & $326(55.2 \%)$ & 1 & $8.00 \mathrm{E}-04$ \\
\hline & & $\mathrm{A} / \mathrm{G}$ & $234(44.1 \%)$ & $229(38.8 \%)$ & $0.60(0.45-0.80)$ & \\
\hline & & $\mathrm{A} / \mathrm{A}$ & $43(8.1 \%)$ & $35(5.9 \%)$ & $0.55(0.32-0.96)$ & \\
\hline & Dominant & $\mathrm{G} / \mathrm{G}$ & $253(47.7 \%)$ & $326(55.2 \%)$ & 1 & $2.00 \mathrm{E}-04$ \\
\hline & & $\mathrm{A} / \mathrm{G}-\mathrm{A} / \mathrm{A}$ & $277(52.3 \%)$ & $264(44.8 \%)$ & $0.59(0.45-0.78)$ & \\
\hline & Recessive & G/G-A/G & 487 (91.9\%) & $555(94.1 \%)$ & 1 & 0.19 \\
\hline & & $\mathrm{A} / \mathrm{A}$ & $43(8.1 \%)$ & $35(5.9 \%)$ & $0.70(0.41-1.20)$ & \\
\hline & Log-additive & - & - & - & $0.67(0.54-0.84)$ & $4.00 \mathrm{E}-04$ \\
\hline \multirow[t]{8}{*}{ rs1056654 } & Codominant & $\mathrm{G} / \mathrm{G}$ & $308(51.2 \%)$ & $307(51.5 \%)$ & 1 & 0.059 \\
\hline & & $\mathrm{A} / \mathrm{G}$ & $238(39.5 \%)$ & $253(42.5 \%)$ & $0.99(0.76-1.30)$ & \\
\hline & & $\mathrm{A} / \mathrm{A}$ & $56(9.3 \%)$ & $36(6 \%)$ & $0.55(0.33-0.92)$ & \\
\hline & Dominant & $\mathrm{G} / \mathrm{G}$ & $308(51.2 \%)$ & $307(51.5 \%)$ & 1 & 0.46 \\
\hline & & $\mathrm{A} / \mathrm{G}-\mathrm{A} / \mathrm{A}$ & $294(48.8 \%)$ & $289(48.5 \%)$ & $0.91(0.70-1.17)$ & \\
\hline & Recessive & $\mathrm{G} / \mathrm{G}-\mathrm{A} / \mathrm{G}$ & $546(90.7 \%)$ & $560(94 \%)$ & 1 & 0.018 \\
\hline & & $\mathrm{A} / \mathrm{A}$ & $56(9.3 \%)$ & $36(6 \%)$ & $0.55(0.34-0.90)$ & \\
\hline & Log-additive & - & - & - & $0.85(0.69-1.04)$ & 0.11 \\
\hline \multirow[t]{3}{*}{ rs2188971 } & Codominant & $\mathrm{C} / \mathrm{C}$ & $295(49 \%)$ & $268(45 \%)$ & 1 & 0.11 \\
\hline & & $\mathrm{T} / \mathrm{C}$ & $250(41.5 \%)$ & $263(44.1 \%)$ & $1.28(0.98-1.69)$ & \\
\hline & & $\mathrm{T} / \mathrm{T}$ & $57(9.5 \%)$ & $65(10.9 \%)$ & $1.45(0.91-2.29)$ & \\
\hline
\end{tabular}

(Continued) 


\begin{tabular}{|c|c|c|c|c|c|c|}
\hline SNP & Model & Genotype & control & case & OR $(95 \% \mathrm{CI})$ & P-value \\
\hline & Dominant & $\mathrm{C} / \mathrm{C}$ & $295(49 \%)$ & $268(45 \%)$ & 1 & 0.04 \\
\hline & & $\mathrm{T} / \mathrm{C}-\mathrm{T} / \mathrm{T}$ & $307(51 \%)$ & $328(55 \%)$ & $1.31(1.01-1.70)$ & \\
\hline & Recessive & $\mathrm{C} / \mathrm{C}-\mathrm{T} / \mathrm{C}$ & $545(90.5 \%)$ & $531(89.1 \%)$ & 1 & 0.26 \\
\hline & & $\mathrm{T} / \mathrm{T}$ & $57(9.5 \%)$ & $65(10.9 \%)$ & $1.28(0.83-1.99)$ & \\
\hline & Log-additive & - & - & - & $1.23(1.01-1.50)$ & 0.038 \\
\hline \multirow[t]{8}{*}{ rs8103163 } & Codominant & $\mathrm{C} / \mathrm{C}$ & $295(48.9 \%)$ & $268(45 \%)$ & 1 & 0.12 \\
\hline & & $\mathrm{A} / \mathrm{C}$ & $251(41.6 \%)$ & $264(44.3 \%)$ & $1.28(0.97-1.68)$ & \\
\hline & & $\mathrm{A} / \mathrm{A}$ & $57(9.4 \%)$ & $64(10.7 \%)$ & $1.42(0.90-2.26)$ & \\
\hline & Dominant & $\mathrm{C} / \mathrm{C}$ & $295(48.9 \%)$ & $268(45 \%)$ & 1 & 0.044 \\
\hline & & $\mathrm{A} / \mathrm{C}-\mathrm{A} / \mathrm{A}$ & $308(51.1 \%)$ & $328(55 \%)$ & $1.31(1.01-1.69)$ & \\
\hline & Recessive & $\mathrm{C} / \mathrm{C}-\mathrm{A} / \mathrm{C}$ & $546(90.5 \%)$ & $532(89.3 \%)$ & 1 & 0.29 \\
\hline & & $\mathrm{A} / \mathrm{A}$ & $57(9.4 \%)$ & $64(10.7 \%)$ & $1.27(0.82-1.97)$ & \\
\hline & Log-additive & - & - & - & $1.23(1.01-1.50)$ & 0.044 \\
\hline \multirow[t]{8}{*}{ rs7248488 } & Codominant & $\mathrm{C} / \mathrm{C}$ & $295(48.9 \%)$ & $268(45 \%)$ & 1 & 0.12 \\
\hline & & $\mathrm{A} / \mathrm{C}$ & $250(41.5 \%)$ & $263(44.1 \%)$ & $1.28(0.98-1.69)$ & \\
\hline & & $\mathrm{A} / \mathrm{A}$ & $58(9.6 \%)$ & $65(10.9 \%)$ & $1.40(0.89-2.21)$ & \\
\hline & Dominant & $\mathrm{C} / \mathrm{C}$ & $295(48.9 \%)$ & $268(45 \%)$ & 1 & 0.044 \\
\hline & & $\mathrm{A} / \mathrm{C}-\mathrm{A} / \mathrm{A}$ & $308(51.1 \%)$ & $328(55 \%)$ & $1.31(1.01-1.69)$ & \\
\hline & Recessive & $\mathrm{C} / \mathrm{C}-\mathrm{A} / \mathrm{C}$ & $545(90.4 \%)$ & $531(89.1 \%)$ & 1 & 0.32 \\
\hline & & $\mathrm{A} / \mathrm{A}$ & $58(9.6 \%)$ & $65(10.9 \%)$ & $1.25(0.81-1.93)$ & \\
\hline & Log-additive & - & - & - & $1.22(1.00-1.49)$ & 0.047 \\
\hline
\end{tabular}

ORs, odds ratios; CI: confidence interval. ${ }^{*} p$ value $\leq 0.05$ indicates statistical significance.

Table 5a: Haplotype frequencies and their associations with CAD risk in ZNF208

\begin{tabular}{lccccccc}
\hline & Rs2188972 & rs2188971 & rs8103163 & rs7248488 & Freq & OR (95\% CI) & P-value \\
\hline 1 & G & C & C & C & 0.495 & 1 & - \\
2 & A & T & A & A & 0.314 & $1.26(1.02-1.55)$ & 0.034 \\
3 & $\mathrm{~A}$ & $\mathrm{C}$ & $\mathrm{C}$ & $\mathrm{C}$ & 0.188 & $1.09(0.85-1.39)$ & 0.520 \\
\hline
\end{tabular}

ORs, odds ratios; CI: confidence interval. ${ }^{*} p$ value $\leq 0.05$ indicates statistical significance.

Table 5b: Haplotype frequencies and their associations with CAD risk in MPHOSPH6

\begin{tabular}{lcccccc}
\hline & rs1056675 & rs1056654 & rs11859599 & Freq & OR (95\% CI) & P-value \\
\hline 1 & C & G & G & 0.427 & 1 & - \\
2 & $\mathrm{~T}$ & $\mathrm{~A}$ & $\mathrm{G}$ & 0.282 & $0.87(0.70-1.09)$ & 0.230 \\
3 & $\mathrm{~T}$ & $\mathrm{G}$ & $\mathrm{C}$ & 0.239 & $1.03(0.82-1.30)$ & 0.780 \\
4 & $\mathrm{~T}$ & $\mathrm{G}$ & $\mathrm{G}$ & 0.051 & $1.57(1.02-2.40)$ & 0.040 \\
\hline
\end{tabular}

ORs, odds ratios; CI: confidence interval. ${ }^{*} p$ value $\leq 0.05$ indicates statistical significance. 
Table 4 shows the genetic models adjusted for age, sex, and smoking. The rs960709 (A/G) polymorphism was positively associated with the risk of $\mathrm{CAD}$ in codominant $\left(\mathrm{OR}=0.55,95 \% \mathrm{CI}=0.32-0.80 ; \mathrm{P}=8^{*} 10^{-4}\right)$, Dominant $(\mathrm{OR}$ $\left.=0.59,95 \% \mathrm{CI}=0.45-0.78 ; \mathrm{P}=2^{*} 10^{-4}\right)$, Log-additive $(\mathrm{OR}=$ $\left.0.67,95 \% \mathrm{CI}=0.54-0.84 ; \mathrm{P}=4^{*} 10^{-4}\right)$. There was significant association between the rs1056654 A/A allele and CAD patients compared to the healthy controls in recessive model $(\mathrm{OR}=0.55,95 \% \mathrm{CI}=0.34-0.90 ; \mathrm{P}=0.018)$. We also found that three SNPS in ZNF208 associated with CAD, respectively, rs2188971 (dominant: $\mathrm{OR}=1.31,95 \% \mathrm{CI}=$ 1.01-1.70, $\mathrm{P}=0.04 ; \mathrm{Log}$ additive: $\mathrm{OR}=1.23,95 \% \mathrm{CI}=$ 1.01-1.50, $\mathrm{P}=0.038$ ); rs8103163(dominant: $\mathrm{OR}=1.31$, $95 \% \mathrm{CI}=1.01-1.69, \mathrm{P}=0.044 ;$ Log additive: $\mathrm{OR}=1.23$, $95 \% \mathrm{CI}=1.01-1.50, \mathrm{P}=0.044)$; rs 7248488 (dominant: $\mathrm{OR}$ $=1.31,95 \% \mathrm{CI}=1.01-1.69, \mathrm{P}=0.044)$.

Linkage disequilibrium (LD) and haplotype analysis of the SNPs in case and control samples were further investigated. The association between the TNIP1 haplotype and the risk of CAD was shown in Table 5a. The study found that the CTA haplotype (rs1056675, rs1056654, rs11859599) was associated with CAD and may be a risk factor for CAD after adjustment $(\mathrm{OR}=$ 1.57; 95\% CI, 1.02-2.40; p =0.040). The LD between the five SNPs were observed (Figure 1). The ZNF208 haplotype and the risk of CAD are listed in Table 5b. Haplotype estimation analysis showed that the haplotype have a significant increased risk of CAD was found in the rs2188972A/rs2188971T/rs8103163A/rs7248488A (ATAA) genotypes compared with the GCCC genotype $(\mathrm{OR}=1.26,95 \% \mathrm{CI}=1.02-1.55 ; \mathrm{P}=0.034)$.

\section{DISCUSSION}

We performed this case-control study to assess the correlation between 15 SNPs in TNIP1, MPHOSPH6 and ZNF208 and the risk of CAD in Chinese Han population. Our results suggested that rs960709 (A) in TNIP1 and rs1065654 (A) in MPHOSPH6 were associated with a decreased risk of CAD. In addition in ZNF208 gene, we found three SNPs (rs2188971, rs8103163, rs7248488) were correlated with a higher risk of CAD.

The ZNF208 gene is located on the human chromosome 19p12. ZNF is the function of the largest human gene family mediated by DNA, RNA, protein interactions, and regulation of gene expression by interacting with other proteins or lipids with a special DNA sequence [22]. They can modulate the expression of genes as a potent transcriptional repressor [23, 24]. To date, only a small number of studies have initiated related studies in ZNF208 regulation of gene expression, with respect to the progression and treatment of several diseases. In recent years, the genome-wide association study (GWAS) of rs8105767 in ZNF208 has been described in relation to telomere length. It was identified to be related to a shortened telomere length and CAD in a European population [25]. Few scholars have studied the association between ZNF208 and CAD until now. The results of this study study suggested that rs2188971, rs8103163 and rs7248488 were indeed associated with the CAD risk. These variants may play a role in regulating gene activity and expression of mRNA, or shortening telomere length and participating in the development of disease.

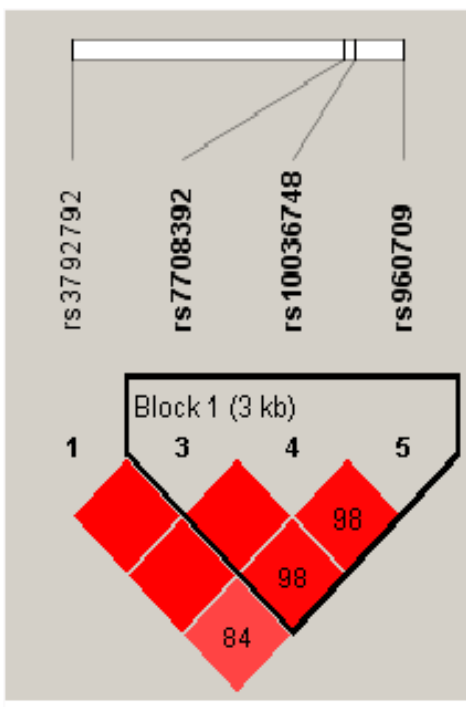

TNIP1

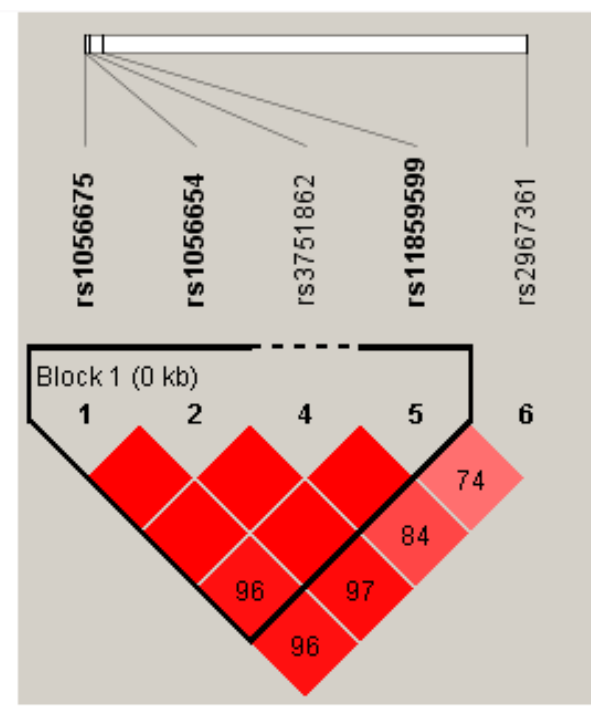

MPHOSPH6

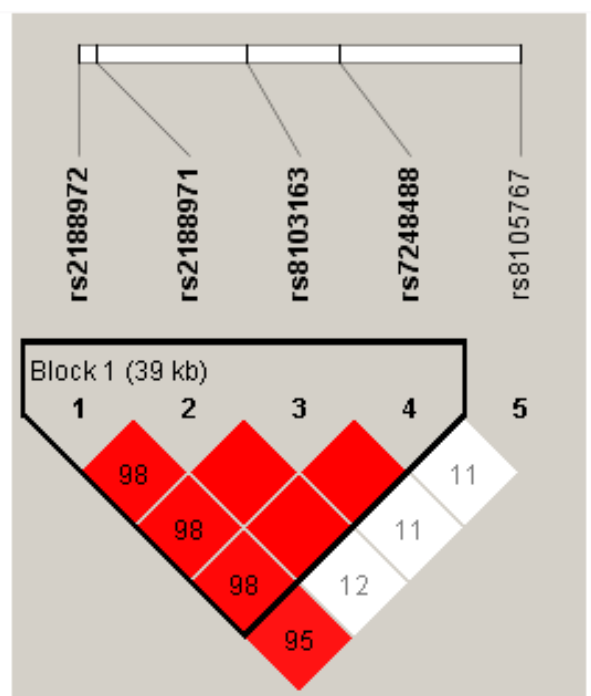

ZNF208

Figure 1: Haplotype block map for the TNIP1, MPHOSPH6 and ZNF208 SNPs genotyped in this study. 
Transcription factor kappa B (NF- $\kappa \mathrm{B})$ is an important regulator of many physiological and pathophysiological processes. It is a transcription factor and plays an important role in inflammation and immune response, cell proliferation and apoptosis. In recent years more attention has been given to the relationship between $N F-\kappa B$ and CAD [26, 27]. Nevertheless NF- $\kappa B$ activity is tightly controlled by several regulatory proteins, such as TNIP1 (ABIN-1) which can inhibit the NF- $\kappa$ B activation induced by tumor necrosis factor, interleukin-1, EGF and lipopolysaccharide $[28,29]$. Loss of protein A20, which binds with the protein (ABIN-1) encoded by the gene TNF $\alpha$-induced protein 3 -interacting protein 1 (TNIP1), resulted in inflammation and autoimmune. Naveed Akbar, et al reported that ABIN-1 was associated with cardiovascular disease in mice [30]. However, present studies mostly focused on the associations between TNIP1 gene polymorphisms and systemic lupus erythematosus [31]. However, up to now, there were fewer reports on the association between TINP1 polymorphisms and CAD risk. Our results indicated rs960709 in TNIP1were found to be associated with the risk of developing CAD.

MPHOSPH6 play an important role in the recruitment of the exosome to the pre-rRNA [32]. MPHOSPH6 may also be involved in regulating shrimp cell cycle and ovary development [33]. MPHOSPH6 is located on chromosome 16q23.3 and encodes the M-phase phosphoprotein 6 (MPP6) that is important for the maturation of 5.8S rRNA. MPP6 is also a RNAbinding protein, which preferentially binds to pyrimidine homopolymers [34].

In our study, we detected five SNPs of MPHOSPH6, and found that genetic polymorphisms of MPHOSPH6 (rs1056654) is associated with CAD, which may shed a new light on the in-depth study for this gene.

In conclusion, the present study provided evidence that SNPs in the TNIP1, ZNF208 and MPHOSPH6 were associated with CAD in Chinese Han population. It is possible that these SNPs are CAD risk factors and these data can provide. While the development of CAD and the relationship between telomerase genes is worth further research.

\section{MATERIALS AND METHODS}

\section{Subjects}

A total of 596 CAD patients, 603 controls were enrolled following institutional ethical approval by Yanan University Affiliated Hospital. All CAD patients were diagnosed according to ischemic heart disease diagnostic criteria issued by WHO in 1979 or the presence of stenosis of more than $50 \%$ luminal diameter in at least one significant coronary artery on coronary angiography angiography. All controls were individuals free of CAD. All these CAD patients and controls were unrelated
Chinese Han people. All participants were interviewed, and data on hypertension, diabetes mellitus, dyslipidemia, medical history including family history, smoking status and duration of CAD were recorded. Baseline clinical characteristics of CAD patients enrolled in this study are summarized in Table 1. Genomic DNA was extracted from the whole blood sample of each patient and control.

\section{Selection of single nucleotide polymorphisms and genotyping}

In this study, fifteen SNPs in TNIP1, MPHOSPH6 and ZNF208 were selected from DbSNP database (http:// www.hapmap.org/index.html.en) and SNP Consortium database (http://snp.cshl.org/) for analysis and each had minor allele frequency (MAF) of $>5 \%$ in Chinese Han population. DNA was isolated from Whole blood were used the GoldMag-Mini Whole Blood Genomic DNA Purification Kit (GoldMag Co. Ltd. Xi'an City, China) extracted. Genotypes for SNPs were determined by Sequenom MassARRAY. We used a NanoDrop 2000 (Gene Company Limited) were measured DNA concentrations. We used Sequenom MassARRAY Assay Design 3.0 Software to design a Multiplexed SNP MassEXTEND assay [35]. The PCR primers for each SNP are shown in Table 2. Data management and analysis was performed using the Sequenom Typer 4.0 Software $[35,36]$.

\section{Statistical analysis}

Hardy-Weinberg equilibrium was tested using a $\chi^{2}$ test to judge the reliability of the gene frequency. Categorical data were analyzed using the chi-square test. $\chi^{2}$ test was performed to assess the distribution of sex, age of CAD among the groups. Allele and genotype frequencies were calculated using the Fisher's exact and Chi square tests, respectively. For association analysis between TNIP1, MPHOSPH6 and ZNF208 and CAD was determined by Odds ratios (ORs) with $95 \%$ confidence intervals (CIs) using Logistic Regression. Multivariate Logistic regression analysis was used to examine the association of clinical and laboratory parameters with different genotype of the SNPs polymorphism with CAD. $\mathrm{P}$ values were used to describe significance. Statistical significance was set as a $\mathrm{P}$ value $<0.05$. All statistical calculations were done using Statistical Package for Social Sciences (SPSS for Windows) software (version 22.0, SPSSInc., Chicago, IL, USA).

\section{ACKNOWLEDGMENTS}

This work was supported by the China Postdoctoral Science Foundation (2016M592835) and Yanan Medical and Health Research Projects (2015KW-04). We thank all of the participants for their involvement in this study. 


\section{CONFLICTS OF INTEREST}

The authors declare that they have no conflicts of interest.

\section{REFERENCES}

1. Teslovich TM, Musunuru K, Smith AV, Edmondson AC, Stylianou IM, Koseki M, Pirruccello JP, Ripatti S, Chasman DI, Willer CJ. Biological, clinical and population relevance of 95 loci for blood lipids. Nature. 2010; 466:707-713.

2. Wild $\mathrm{SH}$, Byrne CD. ABC of obesity. Risk factors for diabetes and coronary heart disease. BMJ. 2006; 333:1009-1011.

3. Jeffrey H, Smith JD. Genome-wide studies of gene expression relevant to coronary artery disease. Curr Opin Cardiol. 2012; 27:210-213.

4. Marenberg ME, Risch N, Berkman LF, Floderus B, De FU. Genetic susceptibility to death from coronary heart disease in a study of twins. N Engl J Med. 1994; 330:1041.

5. Codd V, Mangino M, van der Harst P, Braund PS, Kaiser M, Beveridge AJ, Rafelt S, Moore J, Nelson C, Soranzo N. Common variants near TERC are associated with mean telomere length. Nat Genet. 2010; 42:197.

6. Brouilette S, Singh RK, Thompson JR, Goodall AH, Samani NJ. White cell telomere length and risk of premature myocardial infarction. Arterioscler Thromb Vasc Biol. 2003; 23:842-846.

7. Salpea KD, Talmud PJ, Cooper JA, Maubaret CG, Stephens JW, Abelak K, Humphries SE. Association of telomere length with type 2 diabetes, oxidative stress and UCP2 gene variation. Atherosclerosis. 2010; 209:42-50.

8. Samani NJ, Boultby R, Butler R, Thompson JR, Goodall AH. Telomere shortening in atherosclerosis. Lancet. 2001; 358:472.

9. Weischer M, Bojesen SE, Cawthon RM, Freiberg JJ, Tybjærghansen A, Nordestgaard BG. Short telomere length, myocardial infarction, ischemic heart disease, and early death. Arterioscler Thromb Vasc Biol. 2012; 32:822-829.

10. Haycock PC, Heydon EE, Kaptoge S, Butterworth AS, Thompson A, Willeit P. Leucocyte telomere length and risk of cardiovascular disease: systematic review and metaanalysis. BMJ. 2014; 349:g4227.

11. Willeit P, Willeit J, Brandstätter A, Ehrlenbach S, Mayr A, Gasperi A, Weger S, Oberhollenzer F, Reindl M, Kronenberg F. Cellular aging reflected by leukocyte telomere length predicts advanced atherosclerosis and cardiovascular disease risk. Arterioscler Thromb Vasc Biol. 2010; 30:1649.

12. Serrano AL, Andrés V. Telomeres and cardiovascular disease: does size matter? Circ Res. 2004; 94:575.

13. Maubaret CG, Salpea KD, Romanoski CE, Folkersen L, Cooper JA, Stephanou C, Li KW, Palmen J, Hamsten A,
Neil A. Association of TERC and OBFC1 haplotypes with mean leukocyte telomere length and risk for coronary heart disease. PLoS One. 2012; 8:e83122.

14. Huber M, Treszl A, Wehland M, Winther I, Zergibel I, Reibis R, Bolbrinker J, Stoll M, Schönfelder G, Wegscheider K. Genetic variants implicated in telomere length associated with left ventricular function in patients with hypertension and cardiac organ damage. J Mol Med. 2012; 90:1059-1067.

15. Prowse KR, Greider CW. Developmental and tissue-specific regulation of mouse telomerase and telomere length. Proc Natl Acad Sci U S A. 1995; 92:4818-4822.

16. Coviellomclaughlin GM, Prowse KR. Telomere length regulation during postnatal development and ageing in Mus spretus. Nucleic Acids Res. 1997; 25:3051-3058.

17. Jeanclos E, Schork NJ, Kyvik KO, Kimura M, Skurnick JH, Aviv A. Telomere length inversely correlates with pulse pressure and is highly familial. Hypertension. 2000; 36:195-200.

18. Nzietchueng R, Elfarra M, Nloga J, Labat C, Carteaux JP, Maureira P, Lacolley P, Villemot JP, Benetos A. Telomere length in vascular tissues from patients with atherosclerotic disease. J Nutr Health Aging. 2011; 15:153-156.

19. Okuda K, Bardeguez A, Gardner JP, Rodriguez P, Ganesh V, Kimura M, Skurnick J, Awad G, Aviv A. Telomere length in the newborn. Pediatr Res. 2002; 52:377-381.

20. Takubo K, Izumiyamashimomura N, Honma N, Sawabe M, Arai T, Kato M, Oshimura M, Nakamura K. Telomere lengths are characteristic in each human individual. Exp Gerontol. 2002; 37:523-531.

21. Trudeau MA, Wong JM. Genetic variations in telomere maintenance, with implications on tissue renewal capacity and chronic disease pathologies. Curr Pharmacogenomics Person Med. 2010; 8:7.

22. Eichler EE, Hoffman SM, Adamson AA, Gordon LA, Mccready P, Lamerdin JE, Mohrenweiser HW. Complex beta-satellite repeat structures and the expansion of the zinc finger gene cluster in 19p12. Genome Res. 1998; 8:791-808.

23. Medugno L, Florio F, De CR, Grosso M, Lupo A, Costanzo P, Izzo P. The Krüppel-like zinc-finger protein ZNF224 represses aldolase A gene transcription by interacting with the KAP-1 co-repressor protein. Gene. 2005; 359:35.

24. Lupo A, Cesaro E, Montano G, Izzo P, Costanzo P. ZNF224: structure and role of a multifunctional KRAB-ZFP protein. Int J Biochem Cell Biol. 2011; 43:470-473.

25. Codd V, Nelson CP, Albrecht E, Mangino M, Deelen J, Buxton JL, Hottenga JJ, Fischer K, Esko T, Surakka I. Identification of seven loci affecting mean telomere length and their association with disease. Nat Genet. 2013; 45:422-427.

26. Xian-Jing XU, Huang GR, Duan MQ, Cao XC, Zhao L. Correlation of NF- $\kappa \mathrm{B}$ with clinical types and prognosis of senile CHD. Chin J Health Lab Technol. 2015. 
27. Zou FY, Zou DJ. Correlation study on the NF- $\kappa$ B polymorphismsin Chinese patients with type 2 diabetes. China Med Her. 2007.

28. Huang L, Verstrepen L, K, Wullaert A, Revets H, De-Baetselier P, Beyaert R. ABINs inhibit EGF receptormediated NF-kappaB activation and growth of EGF receptor-overexpressing tumour cells. Oncogene. 2008; 27:6131.

29. Verstrepen L, Carpentier I, Verhelst K, Beyaert R. ABINs: A20 binding inhibitors of NF-kappa B and apoptosis signaling. Biochem Pharmacol. 2009; 78:105-114.

30. Akbar N, Nanda S, Belch J, Cohen P, Khan F. An important role for A20-binding inhibitor of nuclear factor-kB-1 (ABIN1) in inflammation-mediated endothelial dysfunction: an in vivo study in ABIN1 (D485N) mice. Arthritis Res Ther. 2015; 17:1-10.

31. Zhang DM, Cheng LQ, Zhai ZF, Feng L, Zhong BY, You Y, Zhang N, Song ZQ, Yang XC, Chen FR. Single-nucleotide polymorphism and haplotypes of TNIP1 associated with systemic lupus erythematosus in a Chinese Han population. J Rheumatol. 2013; 40:1535-1544.
32. Schilders G, Raijmakers R, Raats JM, Pruijn GJ. MPP6 is an exosome-associated RNA-binding protein involved in 5.8S rRNA maturation. Nucleic Acids Res. 2005; 33:6795.

33. Zhou J, Qiu L, Jiang S, Zhou F, Huang J, Yang L, Su T, Zhang D. Molecular cloning and mRNA expression of M-phase phosphoprotein 6 gene in black tiger shrimp (Penaeus monodon). Mol Biol Rep. 2013; 40:1301.

34. Schilders G, Van DE, Pruijn GJ. C1D and hMtr4p associate with the human exosome subunit PM/Scl-100 and are involved in pre-rRNA processing. Nucleic Acids Res. 2007; $35: 2564$.

35. Gabriel S, Ziaugra L, Tabbaa D. SNP genotyping using the Sequenom MassARRAY iPLEX platform. Curr Protoc Hum Genet. 2009; Chapter 2:Unit 2.12.

36. Thomas RK, Baker AC, Debiasi RM, Winckler W, Laframboise T, Lin WM, Wang M, Feng W, Zander T, Macconaill L. High-throughput oncogene mutation profiling in human cancer. Nat Genet. 2007; 39:347-351. 